\title{
Surface cooling for induction of mild hypothermia in conscious healthy volunteers - a feasibility trial
}

\author{
Christoph Testori ${ }^{1}$, Fritz Sterz ${ }^{1 *}$, Wilhelm Behringer ${ }^{1}$, Alexander Spiel $^{1}$, Christa Firbas $^{2}$ and Bernd Jilma ${ }^{2}$
}

\begin{abstract}
Introduction: Animal and human studies suggest beneficial outcome effects of mild hypothermia for stroke, for acute myocardial infarction, and for cardiogenic shock. The aim of this study was to investigate the feasibility and safety of non-invasive surface cooling for induction and maintenance of mild hypothermia ( 32 to $34^{\circ} \mathrm{C}$ ) in healthy, conscious volunteers.

Methods: The trial was set at a clinical research ward in a tertiary care center, and included 16 healthy male volunteers 18 to 70 years old. Surface cooling was established by a novel non-invasive cooling pad with an esophageal target temperature of 32 to $34^{\circ} \mathrm{C}$ and maintenance for six hours. Shivering-control was achieved with meperidine and buspirone and additional administration of magnesium in eight subjects.

Results: The primary endpoint to reach a target temperature of 32 to $34^{\circ} \mathrm{C}$ was only reached in 6 of the 16 participating subjects. Temperatures below $35^{\circ} \mathrm{C}$ were reached after a median cooling time of 53 minutes (38 to 102 minutes). Cooling rate was $1.1^{\circ} \mathrm{C} / \mathrm{h}\left(0.7\right.$ to $\left.1.8^{\circ} \mathrm{C}\right)$. Additional administration of magnesium had no influence on cooling rate. At no time during the cooling procedure did the participants report uncomfortable conditions for which termination of cooling had to be considered. No severe skin damage was reported.
\end{abstract}

Conclusions: Cooling to body temperature below $35^{\circ} \mathrm{C}$ by the use of non-invasive surface cooling is feasible and safe in conscious healthy volunteers. Further studies are needed to investigate an altered cooling protocol to achieve temperatures below $35^{\circ} \mathrm{C}$.

Trial Registration: ISRCTN: ISRCTN50530495

Keywords: human experimentation, hypothermia, magnesium, myocardial infarction, safety, stroke, temperature

\section{Introduction}

Therapeutic hypothermia improves neurological outcome and reduces the risk of death in patients after cardiac arrest $[1,2]$. In recent years, growing evidence in animal and human studies have documented or suggested the beneficial outcome effects of mild hypothermia also for stroke [3-11], for acute myocardial infarction [12-16], and for cardiogenic shock [17]. Rather than interacting on a particular pathway of postischemic reperfusion damage hypothermia influences multiple reactions leading to cell death [18-20].

\footnotetext{
* Correspondence: fritz.sterz@meduniwien.ac.at

'Department of Emergency Medicine, Medical University of Vienna,

Währinger Gürtel 18-20, 1090 Vienna, Austria

Full list of author information is available at the end of the article
}

So far, the majority of therapeutic hypothermia research has involved cardiac arrest patients, in whom the induction and maintenance of mild hypothermia is facilitated by post-anoxic coma, anesthesia and paralysis to avoid shivering. The typical patient presenting to an emergency department with ischemic stroke or acute myocardial infarction is awake and does not present in a clinical status that necessitates intubation and neuromuscular blockade. The induction of mild hypothermia in these patients remains a challenge. Recent studies investigated various methods for inducing mild hypothermia in awake volunteers or awake patients, such as infusion of cold saline [21,22], surface cooling with circulating chilled water through energy transfer pads placed on the patients' skin $[14,23,24]$, or
Ciomed Central 
endovascular cooling catheters [4,15,25-28]. However, infusion of cold saline does not provide sustained mild hypothermia [29], and cooling devices are bulky and need an electrical power supply, thus preventing the use of these devices in the out-of-hospital setting. Endovascular cooling necessitates the puncture of a main venous blood vessel with all its complications, such as arterial puncture, hematoma, pneumothorax, venous thrombosis and catheter-related infections [30-33]. Recently, a simple to use, non invasive cooling pad, independent of an energy source during use, was developed, which proved to rapidly induce mild hypothermia in patients after cardiac arrest in the out-of-hospital setting [34] and in the emergency department [35].

The aim of this study was to investigate the feasibility and safety of non-invasive surface cooling for induction and maintenance of mild hypothermia $\left(32\right.$ to $34^{\circ} \mathrm{C}$ ) in healthy, conscious volunteers.

\section{Materials and methods Study design}

This study was conducted according to the principles of the Declaration of Helsinki (Version 4, 2004) and was approved by the Ethics Committee of the Medical University of Vienna. This was a prospective interventional study in a cohort of 16 healthy volunteers. Subjects were informed verbally and in writing about the aims of the study. Each volunteer provided written informed consent. Financial compensation was according to standard operating procedures of the Department for Clinical Pharmacology, Medical University of Vienna.

\section{Study setting and population}

Volunteers 18 to 70 years old were included. We excluded pregnant women, subjects with a known preexisting cardiopulmonary disease or pre-existing malignancy, those with pre-existing coagulopathy, with an active dermatologic condition, with a current treatment with monoamine oxidase inhibitors, with previous or current drug abuse, and with a known allergy to the study medication. Core temperature had to be below $37^{\circ}$ $\mathrm{C}$ at the start of the cooling procedure.

\section{Study protocol}

Prior to enrolment, a general health check was performed for each subject. This examination included a general physical examination, lab tests, resting ECG and chest X-ray. Abstinence from alcohol, tobacco and strenuous exercise for 12 hours before the study were requested. Subjects were asked to only consume a light meal before their study day at the research ward to minimize any potential nausea caused by meperidine infusion. Compliance with these requests was confirmed by interview before each trial. Before initiation of cooling, volunteers were asked about any symptoms of infection to avoid aggravation of an incipient disease.

Medication: After baseline measurements, meperidine (Alodan ${ }^{\circledR}$, Gerot, Vienna, Austria) $1 \mathrm{mg} / \mathrm{kg}$ bolus, followed by $30 \mathrm{mg} / \mathrm{h}$ intravenously, and on oral dose of buspirone (Buspar ${ }^{\circledR}$, Bristol-Myers Squibb, Meymac, France) $30 \mathrm{mg}$ was given to prevent shivering. A single bolus of granisetron hydrochloride (Kytril ${ }^{\circledR}$, Roche Austria, Vienna, Austria) $3 \mathrm{mg}$ was administered intravenously to prevent nausea. A continuous fluid drip with an isotonic electrolyte solution (Elomel iso ${ }^{\circledR}$, Fresenius Kabi Austria, Graz, Austria) with an infusion rate of 100 $\mathrm{ml} / \mathrm{h}$ was administered throughout the cooling period. Because of problems reaching the target temperature of 32 to $34^{\circ} \mathrm{C}$ we decided to additionally administer a bolus of $4 \mathrm{~g}$ magnesium sulfate $\left(\mathrm{MgSO}_{4}\right)$ over 30 minutes followed by a continuous intravenous drip of $2 \mathrm{~g} / \mathrm{h}$ for 150 minutes. As such, the administration of magnesium was limited to eight volunteers.

Cooling procedure: The cooling pads (EMCOOLSpad ${ }^{\circledR}$, Emcools AG, Pfaffstaetten, Austria), each $20 \times 30 \mathrm{~cm}$, consist of multiple cooling cells filled with a patented cooling gel. The inner layer is a biocompatible film that adheres to the patient's skin on application and provides intimate pad to skin contact for efficient heat transfer. The cooling units were stored in a cooling box at $-2^{\circ} \mathrm{C}$ before use. Six cooling units were applied on the back, thorax, abdomen and thighs of the volunteers. In previous studies in patients after cardiac arrest, a temperature drop was observed after the removal of the cooling units [34,35]; thus, in this study, the cooling units were removed when a core temperature of $35^{\circ} \mathrm{C}$ was reached. Target core temperature was 32 to $34^{\circ} \mathrm{C}$ and maintained for six hours. The following algorithm was applied to maintain the temperature: if the temperature did not drop below $34.3^{\circ} \mathrm{C}$, or the temperature started to increase before reaching $34.3^{\circ} \mathrm{C}$, two cooling units were applied on the thorax and abdomen, until the temperature reached $34^{\circ} \mathrm{C}$, then the cooling units were removed (cooling units were exchanged when thawed). If the temperature dropped below $33^{\circ} \mathrm{C}$, a warming blanket was applied until the temperature reached $33.1^{\circ} \mathrm{C}$.

After six hours, the volunteers were covered with a blanket and allowed to re-warm. At a temperature of $35^{\circ} \mathrm{C}$, meperidine was stopped, and the volunteers were observed for additional 16 hours.

\section{Measures}

Core temperature was measured continuously with a temperature probe (Mon-a-therm ${ }^{\circledR} 9 \mathrm{Fr} / \mathrm{Ch}$; Tyco Healthcare, Mansfield, MA, USA) advanced into the esophagus, and recorded continuously. The esophageal probe was inserted through the nose. To avoid discomfort and vomiting, local anesthesia with lidocain spray 
2\% (Xylocain $2 \%{ }^{\circledR}$, AstraZeneca GmbH, Wedel, Germany) was applied. Blood pressure was measured noninvasively with Riva-Rocci (Philips Healthcare; Andover, MA, USA), and recorded every 15 minutes. ECG, heart rate and peripheral oxygen saturation were recorded continuously. An intravenous line was placed into a peripheral vein for administration of medication and for blood sampling. A comfort score was recorded every 10 minutes during initial cooling, and every 30 minutes during maintenance cooling. The comfort was measured by a 5 -point scale: 1 = extremely uncomfortable, immediate withdrawal; 2 = very uncomfortable, withdrawal imminent; 3 = unpleasant, no reason for withdrawal at this time; $4=$ no specific sensations, continue the observation; 5 = pleasant sensation, continue the observation. Volunteers were monitored for shivering using a 4-point scale [36]: $0=$ no shivering evident; $1=$ isolated facial or masticatory fasciculation; 2 = peripheral shivering; 3 = uncontrolled rigor. In case of shivering or a comfort score of $\leq 3$, a meperidine $20 \mathrm{mg}$ bolus, followed by an increase of the meperidine drip rate by 5 $\mathrm{mg} / \mathrm{h}$, was given. At the end of the observational period, the skin of all subjects was examined by a dermatologist using a 5-point scale (severe - frost bite; moderate - skin trauma; medium - red skin; mild - pink skin; no visible skin irritation). Due to feasibility and the convenience of the volunteers, the period of active cooling was set at six hours.

\section{Data analysis}

Continuous variables are given as mean \pm standard deviation, or as median and the minimum/maximum range, if not normally distributed. Nominal data are given as counts and percentage of total number. For group comparisons of continuous variables the Student's $t$-test, or the Mann-Whitney-U-test were used. For group comparisons of proportions, the Chi Square test or Fishers Exact test were used. For comparisons within a group, the paired t-test or Wilcoxon Signed Rank test were used. Cooling rates were calculated by the time needed from baseline temperature to an esophageal temperature of $35.0^{\circ} \mathrm{C}$. SPSS software (version 16.0, SPSS Inc., Chicago, IL, USA) and Microsoft Excel (version 12.0 for Mac, Microsoft Corp., Redmond, WA, USA) were used for statistical analysis.

\section{Results}

All 16 healthy male volunteers aged between 21 and 47 years followed the protocol. Median age was 32 years ( 21 to 47 years), and median body mass index was 23.3 $\mathrm{kg} / \mathrm{m}^{2}$ (19.5 to $\left.29.1 \mathrm{~kg} / \mathrm{m}^{2}\right)$; four volunteers were smokers.

In 11 volunteers, all cooling units had to be exchanged before reaching an esophageal temperature of $35^{\circ} \mathrm{C}$, because they were completely thawed. Esophageal temperature decreased from baseline median $36.2^{\circ} \mathrm{C}$ (35.7 to $36.8^{\circ} \mathrm{C}$ ) to $35^{\circ} \mathrm{C}$ within a median time of 53 minutes $(38$ to 102 minutes), which translates into a median cooling rate of $1.1^{\circ} \mathrm{C} / \mathrm{h}\left(0.7\right.$ to $\left.1.8^{\circ} \mathrm{C} / \mathrm{h}\right)$. We found no correlation between body mass index and cooling rate $(P=0.62)$. Only in one volunteer, core temperature dropped below $34^{\circ} \mathrm{C}$ after removal of the six initial cooling units. All volunteers started to rewarm after initial cooling so that two maintenance-cooling units had to be applied and had to be replaced four times (two to five times) because they were completely thawed. Esophageal temperature could be decreased to a minimum temperature of $34.4^{\circ} \mathrm{C}\left(33.7\right.$ to $\left.34.7^{\circ} \mathrm{C}\right)$ during the cooling procedure. An esophageal temperature below $34^{\circ} \mathrm{C}$ could be established in six subjects. After six hours of cooling, esophageal temperature was $34.7^{\circ} \mathrm{C}\left(34.0\right.$ to $\left.35.8^{\circ} \mathrm{C}\right)$. (Figure 1)

There was no statistically significant difference in the time to achieve $35^{\circ} \mathrm{C}$ between those volunteers receiving $\mathrm{MgSO}_{4}$ and those not receiving $\mathrm{MgSO}_{4}$ (48 minutes (38 to 93 minutes) vs. 67 minutes (44 to 102 minutes); $P=$ $0.13)$ ). Minimal temperature reached was significantly lower in volunteers receiving $\mathrm{MgSO}_{4}\left(34.2^{\circ} \mathrm{C}\right.$ (33.7 to $\left.34.4^{\circ} \mathrm{C}\right)$ vs. $34.4^{\circ} \mathrm{C}\left(33.9\right.$ to $\left.\left.34.7^{\circ} \mathrm{C}\right) ; P=0.03\right)$ ). Temperatures at the end of the cooling period were lower in subjects receiving $\mathrm{MgSO}_{4}\left(34.5^{\circ} \mathrm{C}\left(34.0\right.\right.$ to $\left.\left.35.3^{\circ} \mathrm{C}\right)\right)$ as compared to those not receiving $\mathrm{MgSO}_{4}\left(34.8^{\circ} \mathrm{C}\right.$ (34.3 to $\left.35.8^{\circ} \mathrm{C}\right)$ ), although this was not statistically significant $(P$ $=0.09$ ). Serum magnesium levels significantly increased after infusion of the bolus from median $0.87 \mathrm{mmol} / \mathrm{l}$ (0.82 to $0.97 \mathrm{mmol} / \mathrm{l})$ to $1.38 \mathrm{mmol} / \mathrm{l}(1.12$ to 1.51 $\mathrm{mmol} / \mathrm{l} ; P<0.01)$. Plasma concentrations further increased to a level of $1.54 \mathrm{mmol} / \mathrm{l}(1.38$ to $1.59 \mathrm{mmol} /$ 1) at the end of infusion time of 150 minutes and a cumulative dosage of $9 \mathrm{~g} \mathrm{MgSO}$. Magnesium concentrations prior to discharge $(0.90 \mathrm{mmol} / \mathrm{l} ; 0.85$ to 0.98 $\mathrm{mmol} / \mathrm{l})$ were not significantly different from baseline $(P$ $=0.45$ ).

Heart rate, respiratory rate, oxygen saturation and systolic and diastolic blood pressure decreased significantly during cooling (Table 1), but none of the volunteers complained about dizziness or any other signs of hemodynamic impairment. There were no significant differences in the vital signs during the cooling period between volunteers receiving $\mathrm{MgSO}_{4}$ and volunteers not receiving $\mathrm{MgSO}_{4}$, except systolic blood pressure, which was significantly lower in volunteers receiving $\mathrm{MgSO}_{4}$ (113 $\mathrm{mmHg}$ (96 to $121 \mathrm{mmHg}$ ) vs. $122 \mathrm{mmHg}$ (114 to $133 \mathrm{mmHg}) ; P=0.015)$ ).

During the procedure participants never reported uncomfortable conditions necessitating termination of cooling. There was no difference in comfort scale between groups receiving $\mathrm{MgSO} 4$ or not. Shivering was observed in four volunteers (two receiving MgSO4), 


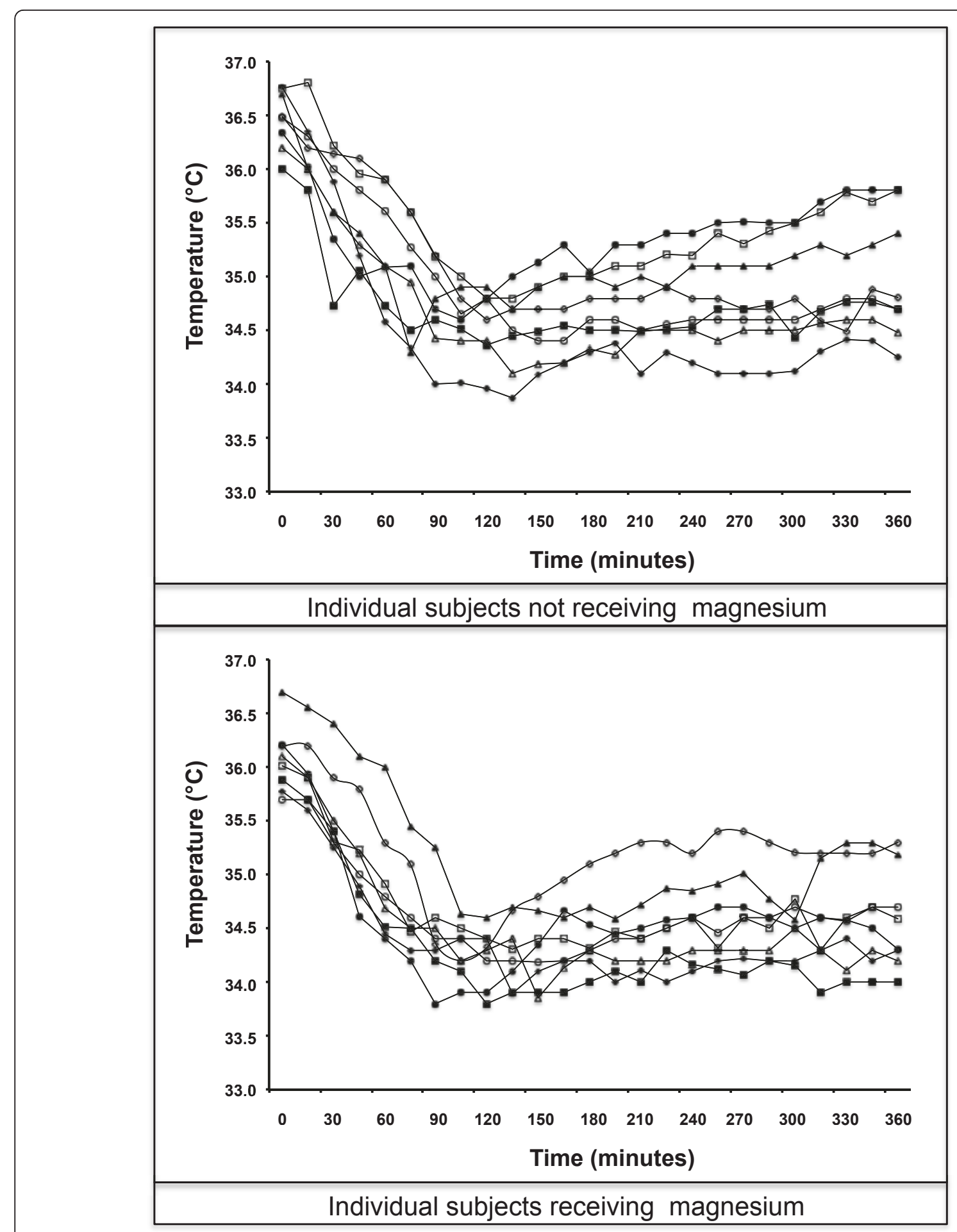

Figure 1 Temperature curves of all subjects. Upper figure: subjects not receiving $\mathrm{MgSO}_{4}$; lower figure: subjects receiving $\mathrm{MgSO}_{4}$.

which could be easily controlled by the adjustment of meperidine drip. Cumulative meperidine dose was 5.8 $\mathrm{mg} / \mathrm{kg}$ (4.1 to $11.5 \mathrm{mg} / \mathrm{kg}$ ) with no difference in patients additionally receiving $\mathrm{MgSO}_{4}$ and those not receiving $\mathrm{MgSO} 4(P=0.75)$.
When removing the cooling pads after initial cooling to a core temperature of $35^{\circ} \mathrm{C}$, red skin was observed in all 16 subjects. After re-warming to temperatures $>36^{\circ}$ $\mathrm{C}$, the skin irritation was no longer evident in two subjects, changed to mild skin irritations (pink skin) in 13 
Table 1 Vital signs

\begin{tabular}{|c|c|c|c|}
\hline & Baseline & Cooling $^{a}$ & $P$-value \\
\hline Heart rate, minute $^{-1}$ & 70 & 49 & $<0.01$ \\
\hline$M M R^{b}$ & 55 to 96 & 43 to 101 & \\
\hline Peripheral oxygen saturation, \% & 98 & 95 & $<0.01$ \\
\hline$M M R^{b}$ & 93 to 100 & 90 to 98 & \\
\hline Respiratory rate, minute-1 & 16 & 10 & $<0.01$ \\
\hline$M M R^{b}$ & 10 to 21 & 7 to 13 & \\
\hline Systolic blood pressure, mmHg & 134 & 117 & $<0.01$ \\
\hline$M M R^{b}$ & 113 to 149 & 96 to 133 & \\
\hline Diastolic blood pressure, $\mathrm{mmHg}$ & 68 & 58 & $<0.01$ \\
\hline$M M R^{b}$ & 54 to 94 & 37 to 67 & \\
\hline
\end{tabular}

${ }^{a}$ lowest value during cooling procedure

${ }^{\mathrm{b}}$ Minimum-maximum range

subjects, and remained as red skin in one subject. Prior to dismissal from the study lab, 10 volunteers still had pink skin. All subjects were followed up for seven days. Skin irritation decreased in all subjects during the follow-up period.

\section{Discussion}

This trial showed that cooling by a novel non-invasive surface cooling pad to temperatures $<35^{\circ} \mathrm{C}$ is feasible and safe in healthy volunteers. Although the primary endpoint to reach a target temperature of 32 to $34^{\circ} \mathrm{C}$ was only reached in 6 of the 16 participating subjects. With the presented study protocol we were not able to achieve predefined ranges of mild hypothermia of 32 to $34^{\circ} \mathrm{C}$.

Most of these patients with acute stroke or acute myocardial infarction are awake and do not present in a clinical status that necessitates intubation and neuromuscular blockade. Furthermore, patients with an acute stroke require serial neurological assessments making deep sedation or anesthesia a contraindication. Meperidine and buspirone were chosen because of their previously described effects on thermoregulation in human beings. The efficacy and use of meperidine and buspirone to suppress shivering have been well described in the anesthesia literature and previous cooling studies [21]. $\mathrm{MgSO}_{4}$ did not markedly improve the cooling rate or comfort of subjects in our study, but might aid to achieve and maintain lower temperatures for a longer time period. In contrast to our results, Zweifler et al. showed that the additional administration of $\mathrm{MgSO}_{4}$ improved the comfort in surface cooling of mildly sedated spontaneously breathing subjects [37]. Zweifler used a bolus infusion of 4 to $6 \mathrm{~g} \mathrm{MgSO}$, followed by a continuous drip of 1 to $3 \mathrm{~g}$ per hour. Taking into account that Zweifer et al. administered $\mathrm{MgSO}_{4}$ over six hours, the cumulative $\mathrm{MgSO}_{4}$ dose was higher in their study. The infusion rate during the first 180 minutes was similar to ours, and so their conclusion is not supported by our data. In our study, a bolus infusion of $4 \mathrm{~g}$ $\mathrm{MgSO}_{4}$, followed by a continuous-drip of $2 \mathrm{~g}$ per hour for 150 minutes significantly reduced systolic blood pressure in our subjects. This finding might be important for future treatment with hypothermia in patients with myocardial infarction and cardiogenic shock, or patients with stroke and hypotension, in whom a further drop in blood pressure will be detrimental.

In a former study in cardiac arrest patients with the same cooling method, cooling was more effective in terms of cooling rate and lowest temperature achieved. [34] This might be explained by the use of only six pads for initial cooling in our study as compared to 10 cooling units used in cardiac arrest patients [34]. In the current study, pads were stored at approximately $-2^{\circ} \mathrm{C}$ as compared with a storage temperature of $-9^{\circ} \mathrm{C}$ in cardiac arrest patients [34]. In addition, awake subjects might have a more evident counter-regulatory response against cooling efforts, as compared with sedated and paralyzed patients after cardiac arrest.

The infusion of cold saline proved to be a simple method to induce mild therapeutic hypothermia in cardiac arrest patients, but needs an additional cooling method to maintain mild hypothermia $[15,38,39]$. However, in awake subjects, cold saline alone might be ineffective to induce mild hypothermia [22]. In addition, the volume load of $30 \mathrm{~mL} / \mathrm{kg}$ to induce mild hypothermia might be harmful in patients with myocardial infarction and left ventricular dysfunction.

Our study has several limitations worth mentioning. The trial was conducted as a feasibility trial in healthy volunteers and may or may not be extrapolated to patients with acute stroke or acute myocardial infarction. Thermoregulation might be different in elderly or sick patients. The major limitation of the study is the fact that the target temperature of 32 to $34^{\circ} \mathrm{C}$ was not achieved in two-thirds of the subjects. This might be due to the removal of the cooling pads at $35^{\circ} \mathrm{C}$, based on our expectation of a more evident drop in temperature after removal of the cooling units as described in cardiac arrest patients [34]. As a consequence, maintenance cooling in the predefined ranges was not achieved. However, in a preliminary study in patients with myocardial infarction, lowering the core temperature to levels of only $35^{\circ} \mathrm{C}$ showed a significant reduction of infarct size. Animal models suggest a more distinctive effect of hypothermia in myocardial infarction if temperature management is initiated early in the prereperfusion period [40]. Recently, Götberg et al. stated that in myocardial infarction, hypothermia should be initiated as soon as possible without delaying reperfusion [41]. Given that this cooling method can be initiated by paramedics in the field, and a core 
temperature of $35^{\circ} \mathrm{C}$ was reached within 53 minutes in the current study, patients with myocardial infarction might be cooled to therapeutic levels of hypothermia already during transport to the hospital.

\section{Conclusions}

Cooling to a body temperature below $35^{\circ} \mathrm{C}$ by the use of non-invasive surface cooling is feasible and safe in conscious, healthy, mildly sedated volunteers. Further studies are needed to investigate: 1 ) an altered cooling protocol to achieve temperatures below $35^{\circ} \mathrm{C}$, and 2) the feasibility and safety of surface cooling with these pads in awake patients with stroke or acute myocardial infarction.

\section{Key messages}

- Surface cooling in healthy, mildly sedated volunteers is feasable and safe.

- An altered cooling protocol is required to achieve lower temperatures. The additional administration of magnesium does not lead to faster cooling rates.

\section{Abbreviations \\ $\mathrm{MgSO}_{4}$ : magnesium sulfate}

\section{Acknowledgements}

This study was sponsored by EMCOOLS AG, Pfaffstätten, Austria. EMCOOLS AG had no influence on collection, analysis and interpretation of data, in the writing of the manuscript, or in the decision to submit the manuscript for publication.

\section{Author details \\ ${ }^{1}$ Department of Emergency Medicine, Medical University of Vienna, Währinger Gürtel 18-20, 1090 Vienna, Austria. ${ }^{2}$ Department of Clinical Pharmacology, Medical University of Vienna, Währinger Gürtel 18-20, 1090 Vienna, Austria.}

\section{Authors' contributions}

CT contributed to the conception and design of the study, the acquisition of the data, the analysis and interpretation of the data, and drafting of the manuscript. FS contributed to the conception and design of the study, the acquisition of the data, the analysis and interpretation of the data and the revision of the manuscript. WB contributed to conception and design of the study and revision of the manuscript. AS and CF contributed to the acquisition of the data and revision of the manuscript. BJ contributed to the conception and design of the study, the acquisition of the data, the analysis and interpretation of the data, and the revision of the manuscript. All authors read and approved the final manuscript

\section{Competing interests}

$C T, C F, B J$ and $A S$ have no competing interests. FS holds a patent relating to the content of the manuscript, but has never received reimbursements, fees, funding or a salary from an organization or company relating to the content of the manuscript. WB is a co-founder, shareholder and paid medical advisor of EMCOOLS (Emergency Medical Cooling Systems AG). EMCOOLS provided the cooling device, but was not involved in creating the design, data management and data analysis of the study, or the manuscript preparation or authorship.

Received: 21 July 2011 Revised: 28 September 2011 Accepted: 22 October 2011 Published: 22 October 2011

\section{References}

1. Hypothermia after Cardiac Arrest Study Group: Mild therapeutic hypothermia to improve the neurologic outcome after cardiac arrest. $N$ Engl J Med 2002, 346:549-556.

2. Bernard SA, Gray TW, Buist MD, Jones BM, Silvester W, Gutteridge G, Smith K: Treatment of comatose survivors of out-of-hospital cardiac arrest with induced hypothermia. N Engl J Med 2002, 346:557-563.

3. Krieger DW, De Georgia MA, Abou-Chebl A, Andrefsky JC, Sila CA, Katzan IL, Mayberg MR, Furlan AJ: Cooling for acute ischemic brain damage (cool aid): an open pilot study of induced hypothermia in acute ischemic stroke. Stroke 2001, 32:1847-1854.

4. Guluma KZ, Hemmen TM, Olsen SE, Rapp KS, Lyden PD: A trial of therapeutic hypothermia via endovascular approach in awake patients with acute ischemic stroke: methodology. Acad Emerg Med 2006, 13:820-827.

5. Schwab S, Georgiardis D, Berrouschot J, Schellinger PD, Graffagnino C, Mayer SA: Feasibility and safety of moderate hypothermia after massive hemispheric infarction. Stroke 2001, 32:2033-2035.

6. Steiner T, Friede T, Aschoff A, Schellinger PD, Schwab S, Hacke W: Effect and feasibility of controlled rewarming after moderate hypothermia in stroke patients with malignant infarction of the middle cerebral artery. Stroke 2001, 32:2833-2835.

7. Kammersgaard LP, Rasmussen BH, Jorgensen HS, Reith J, Weber U, Olsen TS: Feasibility and safety of induction modest hypothermia in awake patients with acute stroke through surface cooling: a case-control study: the Compenhagen Stroke Study. Stroke 2000, 31:2251-2256.

8. Kollmar R, Blank T, Han JL, Georgiadis D, Schwab S: Different degrees of hypothermia after experimental stroke: short- and long-term outcome. Stroke 2007, 38:1585-1589.

9. Clark DL, Penner M, Orellana-Jordan IM, Colbourne F: Comparison of 12, 24 and $48 \mathrm{~h}$ of systemic hypothermia on outcome after permanent focal ischemia in rat. Exp Neurol 2008, 212:386-392.

10. Schöller K, Zausinger S, Baethmann A, Schmid-Elsaesser R: Neuroprotection in ischemic stroke-combination drug therapy and mild hypothermia in a rat model of permanent focal cerebral ischemia. Brain Res 2004, 1023:272-278.

11. van der Worp HB, Sena ES, Donnan GA, Howells DW, Macleod MR: Hypothermia in animal models of acute ischemic stroke: a systematic review and meta-analysis. Brain 2007, 130:3063-3074.

12. Hale SL, Dae MW, Kloner RA: Hypothermia during reperfusion limits 'noreflow' injury in a rabbit model of acute myocardial infarction. Cardiovasc Res 2003, 59:715-722.

13. Dae MW, Gao DW, Sessler DI, Chair K, Stillson CA: Effect of endovascular cooling on myocardial temperature, infarct size, and cardiac output in human-sized pigs. Am J Physiol Heart Circ Physiol 2002, 282:1584-1591.

14. Ly HQ, Denault A, Dupuis J, Vadeboncoeur A, Harel F, Arsenault A, Gibson CM, Bonan R: A pilot study: the Noninvasive Surface Cooling Thermoregulatory System for Mild Hypothermia Induction in Acute Myocardial Infarction (the NICAMI Study). Am Heart J 2005, 150:933.

15. Götberg M, Olivecrona GK, Engblom H, Ugander M, van der Pals J, Heiberg E, Arheden H, Erlinge D: Rapid short-duration hypothermia with cold saline and endovascular cooling before reperfusion reduces microvascular obstruction and myocardial infarct size. BMC CardiovasC Disord 2008, 8:7.

16. Otake H, Shite J, Paredes OL, Shinke T, Yoshikawa R, Tanino Y, Watanabe S, Ozawa T, Matsumoto D, Ogasawara D, Yokoyama M: Catheter-based transcoronary myocardial hypothermia attenuates arrhythmia and myocardial necrosis in pigs with acute myocardial infarction. J Am Coll Cardiol 2007, 49:250-260.

17. Götberg M, van der Pals J, Olivecrona GK, Götberg M, Koul S, Erlinge D: Mild hypothermia reduces acute mortality and improves hemodynamic outcome in a cardiogenic shock pig model. Resuscitation 2010, 81:1190-1196.

18. Polderman $\mathrm{KH}$ : Therapeutic hypothermia in the intensive care unit: problems, pitfalls and opportunities (review). Part 1: Indications and evidence. Intensive Care Med 2004, 30:556-575.

19. Webster CM, Kelly S, Koike MA, Chock W, Giffard RG, Yenari MA: Inflammation and NFkappaB activation is decreased by hypothermia following global cerebral ischemia. Neurobiol Dis 2009, 33:301-312. 
20. Zhao H, Wang JQ, Shimohata T, Sun G, Yenari MA, Sapolsky RM, Steinberg GK: Conditions of protection by hypothermia and effects on apoptotic pathways in a rat model of permanent middle cerebral artery occlusion. J Neurosurg 2007, 107:636-641.

21. Mokhtarani M, Mahgoub AN, Morioka N, Doufas AG, Dae M, Shaughnessy TE, Bjorksten AR, Sessler DI: Buspirone and meperidine synergistically reduce the shivering threshold. Anesth Analg 2001, 93:1233-1239.

22. Moore TM, Callaway CW, Hostler D: Core temperature cooling in healthy volunteers after rapid intravenous infusion of cold and room temperature saline solution. Ann Emerg Med 2008, 51:153-159.

23. Zweifler RM, Voorhees ME, Mahmood MA, Alday DD: Induction and maintenance of mild hypothermia by surface cooling in non-intubated subjects. J Stroke Cerebrovasc Dis 2003, 12:237-243.

24. Abou-Chebl A, DeGeorgia MA, Andrefsky JC, Krieger DW: Technical refinements and drawbacks of a surface cooling technique for the treatment of severe acute ischemic stroke. Neurocrit Care 2004, 1:131-143.

25. Dixon SR, Whitbourn RJ, Dae MW, Grube E, Sherman W, Schaer GL, Jenkins JS, Baim DS, Gibbons RJ, Kuntz RE, Popma JJ, Nguyen T, O'Neill WW: Induction of mild systemic hypothermia with endovascular cooling during primary percutaneuos coronary intervention for acute myocardial infarction. J Am Coll Cardiol 2002, 40:1928-1934.

26. DeGeorgia MA, Krieger DW, Abou-Chebl A, Devlin TG, Jauss M, Davis SM, Koroshetz WJ, Rordorf G, Warach S: Cooling for Acute Ischemic Brain Damage (COOL AID): a feasibility trial of endovascular cooling. Neurology 2004, 63:312-317.

27. Kandzari DE, Chu A, Brodie BR, Stuckey TA, Hermiller JB, Vetrovec GW Hannan KL, Krucoff MW, Christenson RH, Gibbons RJ, Sigmon KN, Garg J, Hasselblad V, Collins K, Harrington RA, Berger PB, Chronos NA, Hochman JS, Califf RM: Feasibility of endovascular cooling as an adjunct to primary percutaneous coronary intervention (results of the LOWTEMP pilot study). Am J Cardiol 2004, 93:636-639.

28. Lyden PD, Allgren RL, Ng K, Akins P, Meyer B, Al-Sanani F, Lutsep H, Dobak J, Matsubara BS, Zivin J: Intravascular Cooling in the Treatment of Stroke (ICTUS): early clinical experience. J Stroke Cerebrovasc Dis 2005, 14:107-114.

29. Kliegel A, Janata A, Wandaller C, Uray T, Spiel A, Losert H, Kliegel M, Holzer M, Haugk M, Sterz F, Laggner AN: Cold infusions alone are effective for induction of therapeutic hypothermia but do not keep patients cool after cardiac arrest. Resuscitation 2007, 73:46-53.

30. McGee DC, Gould MK: Preventing complications of central venous cethterization. N Engl J Med 2003, 348:1123-1133.

31. Raad I: Intravascualrvethter-related infections. Lancet 1998, 351:893-898.

32. Timsit JF, Farkas JC, Boyer JM, Martin JB, Misset B, Renaud B, Carlet J: Central vein catheter-related thrombosis in intensive care patients: Incidence, risk factors, and relationship with catheter-related sepsis. Chest 1998, 114:207-213.

33. Efsing HO, Lindblad B, Mark J, Wolff T: Thromboembolic complications from central venous catheters: A comparision of three catheter materials. World J Surg 1983, 7:419-423.

34. Uray $T$, Malzer R, on behalf of the Vienna Hypothermia After Cardiac Arrest (HACA) Study Group: Out-of-hospital surface cooling to induce mild hypothermia in human cardiac arrest: a feasibility trial. Resuscitation 2008, 77:331-338.

35. Uray T, Haugk M, Sterz F, Arrich J, Richling N, Janata A, Holzer M, Behringer W: Surface cooling for rapid induction of mild hypothermia after cardiac arrest: design determines efficacy. Acad Emerg Med 2010, 17:360-367.

36. Badjatia N, Strongilis E, Gordon E, Prescutti M, Fernandez L, Fernandez A, Buitrago M, Schmidt JM, Ostapkovich ND, Mayer SA: Metabolic impact of shivering during therapeutic temperature modulation: the Bedside Shivering Assessment Scale. Stroke 2008, 39:3242-3247.

37. Zweifler RM, Voorhees ME, Mahmood MA, Parnell M: Magnesium sulfate increases the rate of hypothermia via surface cooling and improves comfort. Stroke 2004, 35:2331-2334.

38. Kim F, Olsufka M, Carlbom D, Deem S, Longstreth WT Jr, Hanrahan M, Maynard C, Copass MK, Cobb LA: Pilot study of rapid infusion of $2 \mathrm{~L}$ of 4 degrees $C$ normal saline for induction of mild hypothermia in hospitalized, comatose survivors of out-of-hospital cardiac arrest. Circulation 2005, 112:715-719.
39. Götberg M, Olivecrona GK, Koul S, Carlsson M, Engblom H, Ugander M, van der Pals J, Algotsson L, Arheden H, Erlinge D: A pilot study of rapid cooling by cold saline and endovascular cooling before reperfusion in patients with ST-elevation myocardial infarction. Circ Cardiovasc Interv 2010, 3:400-407.

40. Miki T, Liu GS, Cohen MV, Downey JM: Mild hypothermia reduces infarct size in the beating rabbit heart: a practical intervention for acute myocardial infarction? Basic Res Cardiol 1998, 93:372-383.

41. Götberg M, van der Pals J, Götberg M, Olivecrona GK, Kanski M, Koul S, Otto A, Engblom H, Ugander M, Arheden H, Erlinge D: Optimal timing of hypothermia in relation to myocardial reperfusion. Basic Res Cardiol 2011, 106:697-708.

doi:10.1186/cc10506

Cite this article as: Testori et al: Surface cooling for induction of mild hypothermia in conscious healthy volunteers - a feasibility trial. Critical Care 2011 15:R248.

\section{Submit your next manuscript to BioMed Central and take full advantage of:}

- Convenient online submission

- Thorough peer review

- No space constraints or color figure charges

- Immediate publication on acceptance

- Inclusion in PubMed, CAS, Scopus and Google Scholar

- Research which is freely available for redistribution 